\title{
The usefulness of routinely used malnutrition screening tools in predicting anemia in lung cancer patients
}

\author{
Katarzyna A. Zabłocka-Słowińska ${ }^{1, A-D}$, Monika Kosacka 2, B, Irena Porębska 2, B, Konrad Pawełczyk 3, B, \\ Marcin Gołecki' ${ }^{2}$, , Jadwiga Biernat ${ }^{4, E, F}$, Halina Grajeta, ${ }^{1, F}, F$ \\ 1 Department of Food Science and Nutrition, Wroclaw Medical University, Poland \\ ${ }^{2}$ Department and Clinic of Pulmonology and Lung Cancers, Wroclaw Medical University, Poland \\ ${ }^{3}$ Department and Clinic of Thoracic Surgery, Wroclaw Medical University, Poland \\ ${ }^{4}$ Department of Human Nutrition, Wroclaw University of Environmental and Life Sciences, Poland \\ A - research concept and design; $\mathrm{B}$ - collection and/or assembly of data; $\mathrm{C}$ - data analysis and interpretation; \\ $\mathrm{D}$ - writing the article; $\mathrm{E}$ - critical revision of the article; $\mathrm{F}$ - final approval of the article
}

\author{
Address for correspondence \\ Katarzyna Zabłocka-Słowińska \\ E-mail: katarzynazablocka0112@gmail.com \\ Funding sources \\ None declared \\ Conflict of interest \\ None declared
}

Received on February 2, 2016

Reviewed on August 7, 2016

Accepted on 0ctober 12, 2016

D0I

$10.17219 /$ acem/65785

\section{Copyright}

Copyright by Author(s)

This is an article distributed under the terms of the

Creative Commons Attribution Non-Commercial License

(http://creativecommons.org/licenses/by-nc-nd/4.0/)

\begin{abstract}
Background. Anemia and malnutrition are frequently observed during lung cancer development, and the associations between them have been researched. However, no study concerning the utility of routinely used nutritional screening tools in predicting anemia in lung cancer has been performed.

Objectives. The aim of this study was to assess the usefulness of routinely used malnutrition screening tools in predicting anemia in lung cancer patients.

Material and methods. Eighty-five male patients were recruited to this study. Blood counts, serum iron concentration, total iron binding capacity (TIBC) and serum transferrin saturation (STS), measurements of selected anthropometric parameters, Mini Nutritional Assessment (MNA) and Glasgow Prognostic Score (GPS) were performed for the subjects. To evaluate the differences in the distribution of hematological and iron status parameters according to nutritional status, a t-test (Mann-Whitney $\mathrm{U}$ test for non-parametric data) and an analysis of variance (ANOVA) were performed. Tukey's post hoc test was performed for intergroup comparison of parametric data. The sensitivity, specificity, positive and negative predictive values of MNA and GPS were compared to blood counts and biochemical parameters of iron status.
\end{abstract}

Results. Using the MNA test, we observed that ca. $60 \%$ of subjects had deteriorated nutritional status. About half of the patients had inflammation cumulated with malnutrition. A similar part of the subjects had anemia. The MNA test showed a significant difference in the distribution of $\mathrm{Hb}$ and $\mathrm{Htc}$, while GPS showed the distribution of $\mathrm{Fe}$ and TIBC among lung cancer patients. We did not observe any influence of fat-free mass index (FFMI) on hematological and iron status parameters. The MNA test had very high specificity and positive predictive values (PPV) for all the hematological parameters evaluated as well as GPS for serum Fe concentration and TIBC.

Conclusions. Our data demonstrates that an evaluation of nutritional status with the MNA test can provide additional predictive information regarding anemia, while GPS may do the same with type of anemia in lung cancer patients.

Key words: lung cancer, malnutrition, anemia, MNA, FFMI 


\section{Introduction}

In the course of lung cancer, accompanying symptoms are often as important as the underlying disease and may influence the treatment schedule. Among a whole range of paraneoplastic symptoms, malnutrition and hematological disturbances, e.g., cancer-related anemia (CRA), often appear, especially among patients in the later stages of lung cancer, those with metastatic disease or among the elderly. ${ }^{1-3}$ The pathomechanism of CRA is different from iron-deficiency anemia (IDA) and similar to anemia of chronic disease (ACD). ACD is usually normochromic and normocytic anemia, and tends to be more severe in cancer patients, where IDA may additionally coexist. The reported prevalence of CRA is about $30 \%$, however data indicates that $60 \%$ or even $90 \%$ of patients with tumors may suffer from anemia. ${ }^{4-7}$ Severe anemia is diagnosed in about $10-20 \%$ of these cases. ${ }^{8}$ This pathological condition generally occurs more often among patients with gastrointestinal tumors or lung cancer patients than others. ${ }^{6,9,10}$ The results of the European Cancer Anemia Survey showed that during diagnosis about $38 \%$ of lung cancer patients were anemic and the prevalence of anemia is associated with the clinical stage of the disease and further the type of treatment. ${ }^{10}$ The pathogenesis of CRA is multifactorial and can result from cancer progression, a coexisting inflammatory process, oncological treatment or the kidney and bone marrow injuries. ${ }^{7,11}$ Decreased erythropoiesis, a predominant mechanism of CRA, is a result of several factors, e.g., reduced erythropoietin synthesis (the kidney injuries or an inflammatory process), and iron, folate and vitamin B12 deficiencies (lack of appetite or deteriorated intestinal absorption and metabolism). Pure red cell aplasia is, in general, observed in patients with hematological malignances and rather does not occur in patients with solid tumors, except thymoma. Destruction or loss of red blood cells (RBC) due to e.g., intestinal bleeding, are other factors that mostly influence the risk of CRA. ${ }^{7}$ Despite the many factors leading to the development of CRA, it is believed that the influence of the inflammatory process is one of the key components of its pathomechanism. ${ }^{12,13}$ The main impact of proinflammatory cytokines in CRA is the disruption in Fe metabolism. Proinflammatory mediators increase hepcidin expression, which blocks Fe flows into plasma, with the resulting effect of the unavailability of Fe for erythropoiesis. ${ }^{14}$ These mediators of inflammation are also, in turn, independent risk factors of cancer malnutrition and cachexia. ${ }^{15,16}$

Malnutrition is common in progressive advanced lung cancer but it may also occur in the early stages of the disease. The prognosis and therapeutic outcome of undernourished lung cancer patients are generally poor. In addition, they are at risk of impaired response to chemo- or radiotherapy, increased susceptibility to chemotherapy-induced toxicity, higher incidence of post-operative complications and generally deterio- rated quality of life and shorter lifespan. ${ }^{17}$ Malnutrition as well as hematological disorders may negatively affect the clinical decision about oncological treatment. ${ }^{18} \mathrm{~A}$ vicious circle may arise between anemia and nutritional disturbances in lung cancer. The altered nutritional status may potentiate the risk of cancer-related anemia due to insufficient nutrient intake and cachexia, which in turn disturbs the metabolism of macro- and micronutrients. On the other hand, anemia may influence the nutritional status due to e.g., loss of appetite. ${ }^{19}$

Awareness of the symptoms associated with lung cancer can be useful for clinicians in the planning and choosing treatment regimens. Since both hematological and nutritional disturbances occur in the course of lung cancer growth and then may potentiate during treatment, it is interesting to evaluate the relationship between them as early as at the stage of disease diagnosis, with simple, routinely used tools evaluating nutritional status. Knowledge of the relationship between anemia and malnutrition, and finding simple tools useful for nutrition evaluation that might also predict anemia incidence, may help to better and more quickly evaluate the condition of patients with lung cancer and, eventually, influence oncological treatment.

The aim of this study was, therefore, to assess the relationship between nutritional status and anemia in lung cancer patients at the stage of diagnosis, using simple, commonly used tools, and to assess the predictive values of the nutritional tools compared to parameters related to anemia.

\section{Material and methods}

Eighty-five male subjects (aged $65.5 \pm 8.6$ years, range: 50-81 years) with newly-diagnosed lung cancer were recruited to this study from the Lower Silesian Center of Lung Diseases. Anthropometric parameters and the MNA test were performed on the day of admission to the hospital. Non-confirmed lung cancer patients were excluded from the study. The majority of patients (74.1\%) suffered from non-small-cell lung cancer (NSCL). The vast majority of recruited subjects (70.7\%) were at clinical stage III and IV lung cancer; about $20.0 \%$ at stage II and a few subjects (9.3\%) at stage I of the disease. Concomitant diseases were reported as follows: cardiovascular diseases (44.7\%), dyslipidemia (35.3\%), impaired fasting glucose (18.8\%), diabetes mellitus type 2 (5.7\%), gastritis and/or stomach ulcers (11.8\%), chronic obstructive pulmonary disease (COPD) (11.8\%), and thyroid diseases (7.1\%). Subjects chronically used the following drugs: cardiovascular agents (48.2\%), statins (16.5\%), $\mathrm{H} 2$ blockers and/or proton pump inhibitors (12.9\%), inhaled agents (glucocorticoids and/or beta2-agonists) (12.9\%), oral antidiabetic agents (7.1\%), insulin (4.8\%), thyroid hormone replacement therapy (3.5\%), and thyreo- 
statics $(2.4 \%)$. The study was approved by the First Local Ethics Commission (approval No. 540/2013) and it conforms to the provisions of the Declaration of Helsinki. Informed consent forms were signed by the subjects who volunteered to participate in the study.

\section{Hematological and iron status parameters}

The parameters related to red blood cells, hemoglobin (Hb) concentration, hematocrit, RBC, mean corpuscular volume $(\mathrm{MCV})$, mean corpuscular hemoglobin $(\mathrm{MCH})$ and mean corpuscular hemoglobin concentration $(\mathrm{MCHC})$ were performed with an automated Sysmex XT-1800i analyzer (Roche Diagnostics, Indianapolis, USA) for recruited patients on the day after admission to the hospital. Serum iron concentration and total iron binding capacity (TIBC) were measured spectrophotometrically using commercial test kits, iron ferrozine (Applied Biosystems cat. No. 11509, Barcelona, Spain) and total iron binding capacity (TIBC) (Applied Biosystems cat. No. 11554, Barcelona, Spain). Blood was taken from the elbow vein between 6:00 and 7:00 am and the parameters related to red blood cells were analyzed the same day. For determination of serum iron concentration and total iron binding capacity, albumin and CRP serum was separated and frozen at $-80^{\circ} \mathrm{C}$ until analysis.

\section{Anthropometric measurement variables}

Body mass and height were self-reported. BMI was calculated as the ratio of the body mass to body height squared and expressed as $\mathrm{kg} / \mathrm{m}^{2}$. Waist and arm circumference were measured twice for every patient on the day of admission to the hospital. Waist circumference (WC) [cm] was measured at the minimum circumference between the iliac crest and the rib cage, and the waistheight ratio (WHtR) was calculated as the ratio of waist circumference divided by the height. Upper arm circumference was measured with the left arm hanging relaxed. The measurement was taken midway between the tip of the acromion and olecranon process. To evaluate fatfree mass index (FFMI) as a sign of muscle wasting, body fat percentage (BFP) [\%] was determined by a bioelectric impedance analysis using a body fat analyzer (Omron BF 306, Kyoto, Japan) 2 times for every patient. Then FFMI was calculated using the following formula:

$$
\text { FFMI }=(100 \%-\text { BFP }) / 100 \times \text { body mass } /(\text { height })^{2}
$$

\section{Mini Nutritional Assessment}

The Mini Nutritional Assessment (MNA) questionnaire is composed of 18 items and involves anthropometric, general, dietary and subjective assessments. Although the questionnaire was originally validated for use in elderly non-malignant patients, some authors have also adapted it for the assessment of cancer patients' nutritional status. ${ }^{3,20,21}$ The questionnaire consists of 2 main parts: screening and assessment. Screening includes questions related to changes in weight loss, oral intake, mobility, stress, etc. Assessment additionally includes medical history, some questions related to eating habits and measurements of arm and calf circumferences. A total score $>23.5$ indicates adequate nutritional status, 17.0-23.5 denotes a risk of malnutrition, while $<17.0$ indicates malnutrition. ${ }^{20}$

\section{Glasgow Prognostic Score}

Glasgow Prognostic Score (GPS) is a cumulative prognostic score based on the systemic inflammatory response and albumin concentration. ${ }^{22}$ Patients with both an elevated C-reactive protein $(>10 \mathrm{mg} / \mathrm{L})$ and hypoalbuminemia $(<35 \mathrm{~g} / \mathrm{L})$ were assigned a score of 2 (group 2). Patients in whom only 1 of these biochemical disturbances was found were allocated a score of 1 (group 1). Patients in whom neither of these abnormalities were present were assigned a score of 0 (group 0 ).

\section{Statistical analysis}

To evaluate the differences in the distribution of hematological and iron status parameters according to nutritional status, a t-test (Mann-Whitney U test for nonparametric data) and an analysis of variance (ANOVA) were performed. Tukey's post hoc test was performed for intergroup comparison of data. All statistical analyses were performed using STATISTICA v. 12.0 (StatSoft, Inc., Tulsa, USA). P-value less than 0.05 was considered to indicate a statistically significant difference.

Sensitivity, specificity, positive (PPV) and negative (NPV) predictive values of the MNA test and GPS were compared to biochemical parameters and calculated from the following formulas:

$$
\begin{gathered}
\text { Sensitivity = a/a + b Eq. (1) } \\
\text { Specificity = c/c + d Eq. (2) } \\
\text { PPV = a/a + d Eq. (3) } \\
\text { NPV = c/c + b Eq. (4) }
\end{gathered}
$$

a - the number of patients who had values of the MNA test or GPS indicating malnutrition or systemic inflammation, respectively, and at the same time a particular biochemical parameter below the reference value (true positive);

$\mathrm{b}$ - the number of patients who had values of the MNA test or GPS indicating proper nutritional status or lack of systemic inflammation, respectively, and at the same time a particular biochemical parameter below the reference value (false negative);

c- the number of patients who had values of the MNA test or GPS indicating proper nutritional status or lack of systemic inflammation, respectively, and at the same time correct particular biochemical parameters (true negative); 
$\mathrm{d}$ - the number of patients who had values of the MNA test or GPS indicating malnutrition or systemic inflammation, respectively, and at the same time correct particular biochemical parameters (false positive).

In calculating sensitivity, specificity, PPV and NPV, the MNA test $<17.0$ and GPS $=2$ were considered as parameters explicitly indicating malnutrition and systemic inflammatory cumulated with malnutrition, respectively. The altered hematological and iron status parameters were defined as those below the reference values (Table 1).

\section{Results}

The baseline nutritional, hematological and iron status of lung cancer patients is presented in Table 1. The MNA test was found to be the most sensitive in screening for malnutrition; ca. $60 \%$ of the group had impaired nutritional status. However, using BMI and AC, only a very small percentage of the subjects studied were found to be malnourished - ca. $1 \%$ for both parameters. About half of the group had both elevated C-reactive protein and hypoalbuminemia expressed as GPS $=2$. Impaired hematological parameters related to anemia were observed in a significant proportion of the group. More than $40 \%$ of the subjects had $\mathrm{Hb}$ below reference values. ${ }^{23}$ Low Htc was observed in ca. $70 \%$ of patients and low RBC in about half of the group. ${ }^{24}$ Moreover, low TIBC, which is mostly seen in anemia of chronic disease, was found in almost $60 \%$ of the group. ${ }^{25}$

\section{Prevalence of anemia according to nutritional status}

The high sensitivity of the MNA test gave us the opportunity to evaluate the distribution of hematological and iron status parameters according to the results of this test (Table 2). Indeed, we found that $\mathrm{Hb}$ concentration and Htc were significantly lower in malnourished patients compared to well-nourished ones. Similar trends were observed in the other evaluated parameters, except $\mathrm{MCH}$ and $\mathrm{MCHC}$, however these observations were not statistically significant. The distributions of all the hematological and iron status parameters according to FFMI did not differ significantly between the groups (Table 3). Even so, almost all the parameters tended to be higher in the well-nourished group vs the group with risk of malnutrition. The distribution of the parameters according to the prevalence of systemic inflammation disclosed a significantly lower serum iron concentration and TIBC in the group with systemic inflammation (Table 4). Interestingly, we did not find any meaningful differences in the remaining parameters, e.g., $\mathrm{Hb}$ concentration, Htc, $\mathrm{RBC}$ and the parameters of red blood cells.

\section{Sensitivity, specificity, PPV and NPV of the MNA test and GPS compared to hematological and iron status}

The MNA test had very low sensitivity, oscillating around $20 \%$, when compared to blood parameters (Table 5). However, this test was shown to have high specificity, close to $90 \%$ or even $100 \%$, when compared to TIBC. Additionally, we observed high PPV for the MNA test when compared to TIBC (100\%) and Htc (ca. 85\%). The sensitivity, specificity, PPV and NPV of GPS were low in general when compared to the parameters related to red blood cells and iron status. However, relatively high PPV was found when compared to Fe (ca. 73\%) and TIBC (75\%).

\section{Discussion}

Lung cancer represents a significant clinical concern, accounting for the highest mortality and morbidity of all cancers, especially among men. ${ }^{26}$ Anemia and malnutrition were recognized in several studies as good indicators of lung

Table 1. Baseline nutritional, hematological and iron status of male lung cancer patients

\begin{tabular}{|c|c|c|c|c|c|}
\hline Parameter & $\mathrm{N}$ & $\begin{array}{c}\text { Reference } \\
\text { values }\end{array}$ & Range & Mean $(95 \% \mathrm{Cl})$ & $\begin{array}{c}\% \text { of group } \\
\text { under (*over) } \\
\text { the reference } \\
\text { values }\end{array}$ \\
\hline BMI $\left[\mathrm{kg} / \mathrm{m}^{2}\right]$ & 85 & $18.5-25.0$ & $17.9-45.8$ & $25.9(24.9-26.9)$ & 1.2 \\
\hline FFMI $\left[\mathrm{kg} / \mathrm{m}^{2}\right]$ & 80 & $>17.0$ & $14.9-25.4$ & $18.9(18.5-19.5)$ & 22.5 \\
\hline $\mathrm{AC}[\mathrm{cm}]$ & 85 & $>21$ & $19-36.5$ & $27.2(26.5-27.9)$ & 1.2 \\
\hline WHtR & 84 & $\leq 0.5$ & $0.42-0.79$ & 0.59 & $89.4^{*}$ \\
\hline MNA [points] & 82 & $>23.5$ & $9-28.5$ & $21.4(20.4-22.4)$ & 58.9 \\
\hline GPS 0/1/2 [\%] & 53 & - & $35.8 / 14.2 / 50.9$ & - & - \\
\hline $\mathrm{Hb}[\mathrm{g} / \mathrm{dL}]$ & 85 & $>13$ & $8.3-16.9$ & $13.1(12.7-13.4)$ & 44.7 \\
\hline $\mathrm{Htc}[\%]$ & 85 & $>41$ & & 38.9 (38.0-39.8) & 69.4 \\
\hline $\mathrm{RBC}$ & 85 & $>4.4$ & $2.9-5.4$ & $4.4(4.3-4.5)$ & 51.8 \\
\hline $\mathrm{MCV}[\mathrm{fL}]$ & 26 & $>82$ & $74.6-96.8$ & $87.2(85.3-89.0)$ & 8.2 \\
\hline $\mathrm{MCH}[\mathrm{pg}]$ & 26 & $>27$ & $23.9-33.7$ & $29.2(28.2-30.2)$ & 18.9 \\
\hline $\mathrm{MCHC}[\mathrm{g} / \mathrm{dL}]$ & 26 & $>31.5$ & $30.8-37.3$ & $33.5(32.8-34.2)$ & 8.2 \\
\hline $\mathrm{Fe}[\mu \mathrm{g} / \mathrm{dL}]$ & 65 & $65-175$ & $11.6-226.3$ & 78.9 (65.5-92.3) & 40.0 \\
\hline $\mathrm{TIBC}[\mu \mathrm{g} / \mathrm{dL}]$ & 64 & $250-450$ & $23.6-379.1$ & $190.6(170.5-210.8)$ & 58.8 \\
\hline STS [\%] & 64 & $20-50$ & $5.5-90.7$ & $35.6(29.9-41.4)$ & 16.5 \\
\hline
\end{tabular}

$\mathrm{Cl}$ - confidence interval; BMI - body mass index; FFMI - fat-free mass index; AC - arm circumference; WHtR - waist-height ratio; MNA - Mini Nutritional Assessment; GPS Glasgow Prognostic Score; Hb - hemoglobin; Htc - hematocrit; RBC - red blood cell; MCV - mean corpuscular volume; MCH - mean corpuscular hemoglobin; MCHC - mean corpuscular hemoglobin concentration; TIBC - total iron binding capacity; STS - serum transferrin saturation. 
Table 2. Distribution of hematological parameters according to MNA test results

\begin{tabular}{|l|c|c|c}
$\begin{array}{l}\text { Hematological } \\
\text { parameter }\end{array}$ & Well-nourished & Risk of malnutrition & Malnutrition \\
\hline $\mathrm{Hb}[\mathrm{g} / \mathrm{dL}]$ & $13.6(13.0-14.2) \pm 1.6^{\mathrm{a}}$ & $12.8(12.3-13.4) \pm 1.5^{\mathrm{ab}}$ & $13.6(13.0-14.2) \pm 1.7^{\mathrm{b}}$ \\
\hline $\mathrm{HtC}[\%]$ & $40.4(39.0-41.8) \pm 4 .^{\mathrm{a}}$ & $38.2(36.9-39.5) \pm 3.7^{\mathrm{ab}}$ & $37.3(35.0-39.7) \pm 4.0^{\mathrm{b}}$ \\
\hline $\mathrm{RBC}$ & $4.5(4.1-4.6) \pm 0.5$ & $4.3(4.1-4.4) \pm 0.5$ & $4.3(4.1-4.6) \pm 0.5$ \\
\hline $\mathrm{MCV}[\mathrm{fL}]$ & $88.4(86.0-90.8) \pm 3.4$ & $87.1(84.2-89.9) \pm 4.5$ & $84.3(73.2-95.5) \pm 7.0$ \\
\hline $\mathrm{MCH}[\mathrm{pg}]$ & $27.3(22.6-32.1) \pm 3.0$ & $29.3(27.8-30.9) \pm 2.5$ & $29.9(28.4-31.4) \pm 2.1$ \\
\hline $\mathrm{MCHC}[\mathrm{g} / \mathrm{dL}]$ & $33.8(32.4-34.6) \pm 1.6$ & $33.6(32.6-34.6) \pm 1.6$ & $33.8(32.4-35.1) \pm 1.8$ \\
\hline $\mathrm{Fe}[\mu \mathrm{g} / \mathrm{dL}]$ & $83.4(61.8-105.0) \pm 58.8$ & $78.9(59.1-98.8) \pm 48.1$ & $63.2(20.2-106.1) \pm 55.9$ \\
\hline $\mathrm{TIBC}[\mu \mathrm{g} / \mathrm{dL}]$ & $211.8(185.9-237.6) \pm 70.4$ & $177.1(139.2-214.9) \pm 89.6$ & $153.9(95.3-212.5) \pm 76.2$ \\
\hline $\mathrm{STS}[\%]$ & $36.2(27.2-45.1) \pm 23.1$ & $35.9(25.40-046.6) \pm 21.7$ & $33.2(20.9-45.6) \pm 14.8$ \\
\hline
\end{tabular}

MNA - Mini Nutritional Assessment; Hb - hemoglobin; Htc - hematocrit; RBC - red blood cell; MCV - mean corpuscular volume; $\mathrm{MCH}$ - mean corpuscular hemoglobin; MCHC - mean corpuscular hemoglobin concentration; TIBC - total iron binding capacity; STS - serum transferrin saturation; $a, b$ - statistically significant differences in hematological parameters between patients with different nutritional status according to the MNA test (ANOVA test).

Table 3. Distribution of hematological parameters according to FFMI results

\begin{tabular}{|l|c|c|}
$\begin{array}{c}\text { Hematological } \\
\text { status }\end{array}$ & Well-nourished & Risk of malnutrition \\
\hline $\mathrm{Hb}[\mathrm{g} / \mathrm{dL}]$ & $13.2(12.8-13.6) \pm 1.7$ & $12.5(11.7-13.3) \pm 1.6$ \\
\hline $\mathrm{HtC}[\%]$ & $39.2(38.2-40.2) \pm 4.0$ & $37.7(35.5-39.8) \pm 4.3$ \\
\hline $\mathrm{RBC}$ & $4.4(4.3-4.5) \pm 0.4$ & $4.2(3.9-4.5) \pm 0.6$ \\
\hline $\mathrm{MCV}[\mathrm{fL}]$ & $87.9(86-89.8) \pm 4.1$ & $84.2(77.3-91.1) \pm 5.6$ \\
\hline $\mathrm{MCH}[\mathrm{pg}]$ & $29.6(28.5-30.6) \pm 2.3$ & $27.9(24.1-31.7) \pm 3.1$ \\
\hline $\mathrm{MCHC}[\mathrm{g} / \mathrm{dL}]$ & $33.6(32.8-34.3) \pm 1.6$ & $33.1(30.7-35.6) \pm 2.0$ \\
\hline $\mathrm{Fe}[\mu \mathrm{g} / \mathrm{dL}]$ & $75.5(61.6-89.3) \pm 48.7$ & $90.2(51.5-128.9) \pm 69.9$ \\
\hline $\mathrm{TIBC}[\mu \mathrm{g} / \mathrm{dL}]$ & $196.9(173.8-220.0) \pm 80.4$ & $170.2(125.3-215.0) \pm 81.0$ \\
\hline $\mathrm{STS}[\%]$ & $32.9(27.1-38.7) \pm 18.7$ & $44.5(28.1-60.8) \pm 27.1$ \\
\hline
\end{tabular}

FFMI - fat-free mass index; Hb - hemoglobin; Htc - hematocrit; RBC - red blood cell; MCV - mean corpuscular volume; MCH - mean corpuscular hemoglobin; MCHC - mean corpuscular hemoglobin concentration; TIBC - total iron binding capacity; STS - serum transferrin saturation.

Table 4. Distribution of hematological parameters according to GPS results

\begin{tabular}{|l|c|c|}
$\begin{array}{l}\text { Hematological } \\
\text { status }\end{array}$ & Score 0-1 & Score 2 \\
\hline $\mathrm{Hb}[\mathrm{g} / \mathrm{dL}]$ & $13.4(12.7-14.1) \pm 1.7$ & $13.1(12.4-13.7) \pm 1.6$ \\
\hline $\mathrm{HtC}[\%]$ & $39.7(38.2-41.2) \pm 3.6$ & $39.3(37.6-40.9) \pm 4.2$ \\
\hline $\mathrm{RBC}$ & $4.5(4.3-4.6) \pm 0.3$ & $4.4(4.2-4.6) \pm 0.5$ \\
\hline $\mathrm{MCV}[\mathrm{fL}]$ & $87.5(85.2-89.8) \pm 3.0$ & $87.1(84.1-80.1) \pm 5.4$ \\
\hline $\mathrm{MCH}[\mathrm{pg}]$ & $30.0(28.2-31.9) \pm 2.5$ & $28.8(27.4-30.2) \pm 2.5$ \\
\hline $\mathrm{MCHC}[\mathrm{g} / \mathrm{dL}]$ & $34.3(32.8-35,8) \pm 1.9$ & $33.0(32.2-33.8) \pm 1.5$ \\
\hline $\mathrm{Fe}[\mu \mathrm{g} / \mathrm{dL}]$ & $89(65.6-112.5) \pm 55.5^{*}$ & $62.4(41.7-83.2) \pm 50.3^{*}$ \\
\hline $\mathrm{TIBC}[\mu \mathrm{g} / \mathrm{dL}]$ & $240.3(210.4-270.2) \pm 69.2^{*}$ & $166.5(135.2-197.8) \pm 75.8^{*}$ \\
\hline $\mathrm{STS}[\%]$ & $35.8(26.0-45.8) \pm 21.9$ & $33.5(25.0-42.0) \pm 19.7$ \\
\hline
\end{tabular}

GPS - Glasgow Prognostic Score; Hb - hemoglobin; Htc - hematocrit; $\mathrm{RBC}$ - red blood cell; MCV - mean corpuscular volume; $\mathrm{MCH}$ - mean corpuscular hemoglobin; MCHC - mean corpuscular hemoglobin concentration; TIBC - total iron binding capacity; STS - serum transferrin saturation; * statistically significant differences in hematological variables between patients with different GPS results. cancer and other cancer progression. Moreover, the association between them has been investigated by several authors. ${ }^{27-29}$ However, to the best of our knowledge, there has been no study concerning the relationship between nutritional status evaluated by simple, routinely used anthropometric parameters and the MNA test, and parameters related to red blood cells and iron status in lung cancer patients. Moreover, the study evaluated the relationship between anemia and inflammation using Glasgow Prognostic Score in this condition. These points of view could bring new insights and opportunities to the evaluation of the relationship between malnutrition and anemia.

Of all the parameters used in this study to assess nutritional status, the MNA test was found to detect the highest percentage of the group with malnutrition or risk of malnutrition. This result indicating the high sensitivity of the MNA test is in agreement with other studies, where the MNA test was recommended as a useful tool for the evaluation of nutritional status in this condition. ${ }^{2,3,29}$ However, we did not find more than 2 studies which assess the relationship between the MNA test and hematological parameters among lung cancer patients. Gioulbasanis et al. showed that the MNA test was significantly correlated with $\mathrm{Hb}$ but they did not evaluate the association with other parameters related to red blood cells. ${ }^{3,29}$ Another study clearly demonstrated a significant correlation between the MNA test and laboratory parameters indicating hematological disorders. ${ }^{30}$ However, this research concerned elderly people living in nursing homes, not cancer patients. In our study, we found that the MNA test was correlated with $\mathrm{Hb}$ and Htc. Despite this, we did not observe significant differences in other hematological parameters and parameters related to iron

Table 5. Sensitivity, specificity, PPV and NPV of MNA and GPS* compared to blood parameters

\begin{tabular}{|l|c|c|c|c|}
$\begin{array}{c}\text { Hematological } \\
\text { parameter }\end{array}$ & Sensitivity & Specificity & PPV & NPV \\
\hline $\mathrm{Hb}[\mathrm{g} / \mathrm{dL}]$ & $23.7 ; 50.0$ & $90.9 ; 44.0$ & $69.2 ; 46.2$ & $57.9 ; 47.8$ \\
\hline $\mathrm{HtC}[\%]$ & $18.9 ; 53.1$ & $91.7 ; 41.2$ & $84.6 ; 63.0$ & $31.9 ; 31.8$ \\
\hline $\mathrm{RBC}$ & $18.6 ; 52.4$ & $87.2 ; 44.4$ & $61.5 ; 42.3$ & $49.3 ; 54.5$ \\
\hline $\mathrm{Fe}[\mu \mathrm{g} / \mathrm{dL}]$ & $17.6 ; 61.3$ & $90.3 ; 46.2$ & $66.7 ; 73.1$ & $50.0 ; 33.3$ \\
\hline $\mathrm{TIBC}[\mu \mathrm{g} / \mathrm{dL}]$ & $18.3 ; 64.3$ & $100 ; 64.7$ & $100 ; 75.0$ & $25.9 ; 52.4$ \\
\hline
\end{tabular}

* The first value in every column corresponding to MNA, the second to GPS; PPV - positive predictive value; NPV - negative predictive value; MNA - Mini Nutritional Assessment; GPS - Glasgow Prognostic Score; $\mathrm{Hb}$ - hemoglobin; Htc - hematocrit; RBC - red blood cell; TIBC - total iron binding capacity. 
status in patients with different results of the MNA test. One reason could presumably be due to high prevalence of inflammation among the subjects. Based on the Guigoz's review, it was found that the presence of inflammation may significantly change the correlations between laboratory parameters and the MNA test. ${ }^{31}$ This observation may, in particular, clarify the lack of significant differences in TIBC and serum iron concentration between patients assessed only on the basis of their nutritional status, without evaluating the presence of inflammation, where inflammation could have presumably influenced the concentration of these parameters to a great extent. Indeed, we observed significantly lower TIBC and iron concentration in group 2 compared to the rest of the subjects, assigned depending on GPS. Statistically significant differences in these 2 parameters were observed only when the cut-off point for GPS score was set at 2 (high C-reactive protein, low albumin concentration). No meaningful differences were found when patients were distributed into 3 groups, based on GPS score. This indicates that only inflammation and malnutrition together may have a great impact on some hematological parameters.

Cancer-related anemia is closely linked to systemic inflammation and malnutrition. ${ }^{28}$ This explains the lower TIBC and iron concentration in group 2 compared to the remaining participants. Hypoferremia, often observed in cancer patients, is induced by impaired reutilization of iron. It is caused by reduced iron release from macrophages to circulating transferrin. During the inflammatory process, cytokines, e.g., IL-6, potentiate hepcidin synthesis, causing iron sequestration in the macrophages. ${ }^{32}$ Moreover, during inflammation, the concentration of transferrin drops in connection with the disturbed metabolism of this protein. ${ }^{33}$ Therefore, low TIBC, which is an indirect measure of serum transferrin, and low serum iron concentration are commonly seen with anemia of chronic disease or with inflammation. Other than this, we did not find any significant differences in the remaining parameters between the groups of patients distinguished by GPS results, although there was a tendency toward lower blood parameters in the group with systemic inflammation. In fact, it is difficult to explain why lung cancer patients with systemic inflammation and malnutrition had no other hematological parameters that were significantly lower. One explanation may be that a meaningful proportion of the subjects were at an advanced stage of the disease, which had influenced to a great extent many different metabolic processes which indirectly affect erythropoiesis. For example, the caloric malnutrition often observed in patients with the advanced disease may lead to disturbed transformation of tetraiodothyronine to triiodothyronine (functional hypothyroidism), in which anemia is induced by a reduction in the synthesis of erythropoietin. ${ }^{34}$ This example also suggests other factors, aside from inflammation and protein-malnutrition, influencing the risk of anemia in cancer patients.

Additionally, to better assess the usefulness of the MNA test and GPS in predicting the prevalence of anemia, we describe them by terms such as sensitivity, specificity, PPVs and NPVs. We found that the MNA test had high specificity and low sensitivity when compared to blood parameters. These results demonstrate that this test might be useful in blood disorders for determining if this parameter indicates malnutrition. However, as was stated by Akobeng, the high value of specificity of the MNA test cannot be used to estimate the probability of hematological disorders in an individual patient. ${ }^{35}$ The major limitations of both the sensitivity and specificity values is that they are of no practical use to clinicians in evaluating the probability of disturbances in an individual patient. PPVs and NPVs are more useful rather in describing the probability that the test will give the correct diagnosis. In this study, the MNA test had high PPVs when compared to all measured biochemical parameters, and GPS when compared to iron concentration and TIBC. These findings suggest that the MNA test and GPS may bring additional information about anemia incidence and type of anemia in lung cancer.

Several limitations need to be acknowledged in this study. Although the majority of recruited patients had stage III and IV of the disease, the group was not fully homogenous for clinical stage; the same problem concerned the histological type of cancer. This diversity could influence the evaluated relationships.

\section{Conclusions}

Our data demonstrates that evaluation of nutritional status with the MNA test can provide additional predictive information regarding anemia, while GPS can help to predict the type of anemia in lung cancer patients and possibly in patients with other types of cancer. However, further, more detailed studies are needed to determine these relationships.

\section{References}

1. Gascón P, Almenárez J, Artal Á, et al. Management of lung cancer-associated anemia: The Spanish Lung Cancer Anemia Survey (SLCAS). Clin Transl Oncol. 2008;13:328-334.

2. Zhang $L$, Su $Y$, Wang $C$, et al. Assessing the nutritional status of elderly Chinese lung cancer patients using the Mini Nutritional Assessment (MNA ${ }^{\circ}$ ) tool. Clin Int Aging. 2013;8:287-291.

3. Gioulbasanis I, Baracos VE, Giannousi Z, et al. Baseline nutritional evaluation in metastatic lung cancer patients: Mini Nutritional Assessment versus weight loss history. Ann Oncol. 2011;22:835-841.

4. Weiss G. Anemia of chronic disorders: New diagnostic tools and new treatment strategies. Sem Hematol. 2015;52:313-320.

5. Caro JJ, Salas M, Ward A, Goss G. Anemia as an independent prognostic factor for survival in patients with cancer. Cancer. 2001;91:2214-2221.

6. Aapro M, Österborg A, Gascon P, Ludwig H, Beguin Y. Prevalence and management of cancer-related anaemia, iron deficiency and the specific role of i.v. iron. Ann Oncol. 2012;23:1954-1962.

7. Gilreath JA, Stenehjem DD, Rodgers GM. Diagnosis and treatment of cancer-related anemia. Am J Hematol. 2014;89:203-212.

8. Dwilewicz-Trojaczej J. Anemia and cancer. Contemporary Oncol. 2004;8:15-19.

9. Ludwig H, Müldür E, Endler G, Hübl W. Prevalence of iron deficiency across different tumors and its association with poor performance status, disease status and anemia. Ann Oncol. 2013;24(7):1886-1892. 
10. Kosmidis $P$, Krzakowski $M$, the ECAS Investigators: Anemia profiles in patients with lung cancer: What have we learned from the European Cancer Anaemia Survey (ECAS)? Lung Cancer. 2005;50:401-412.

11. Dicato M. Anemia in cancer: Some pathophysiological aspects. The Oncologist. 2003;8:19-21.

12. Aleksandrakis MG, Passam FH, Perisinakis K, et al. Serum proinflammatory cytokines and its relationship to clinical parameters in lung cancer patients with reactive thrombocytosis. Respir Med. 2002;96:553-558.

13. Girelli D, Nemeth E, Swinkels DW. Hepcidin in the diagnosis of iron disorders. Blood. 2016;127:2809-2813.

14. Theurl I, Aigner E, Theurl M, et al. Regulation of iron homeostasis in anemia of chronic disease and iron deficiency anemia: Diagnostic and therapeutic implications. Blood. 2009;113:5277-5286.

15. Correia M, Cravo M, Marques-Vidal $P$, et al. Serum concentrations of TNF- $a$ as a surrogate marker for malnutrition and worse quality of life in lung cancer patients. Clin Nutr. 2007;26:728-735.

16. Songür N, Kuru B, Kalkan F, Özdilekcan Ç, Çakmak H, Hizel N Serum interleukin- 6 level correlated with malnutrition and survival in patients with advanced non-small cell lung cancer. Tumori. 2004;90:196-200.

17. Argiles JM. Cancer-associated malnutrition. Eur J Oncol Nurs. 2005;9:39-50.

18. Santarpia L, Contaldo F, Pasanisi F. Nutritional screening and early treatment of malnutrition in cancer patients. J Cachexia, Sarcopenia Muscle. 2011;2:27-35.

19. Alexandre J, Gross-Goupil M, Falissard B, et al. Evaluation of the nutritional and inflammatory status in cancer patients for the risk assessment of severe haematological toxicity following chemotherapy. Ann Oncol. 2003;14:36-41.

20. Cereda E. Mini Nutritional Assessment. Curr Opin Clin Nutr Metab Care. 2012;15:29-41.

21. Liu P, Yan X, Wang B, Xu X. Three methods assess nutritional status of leukemia patients before hematopoietic stem cell transplantations. Chinese Med J. 2012;125:440-443.

22. Forrest LM, McMillan DC, McArdle CS, Angerson WJ, Dunlop DJ. Evaluation of cumulative prognostic scores based on the systemic inflammatory response in patients with inoperable non-small-cell lung cancer. Br J Cancer. 2003;89:1028-1030.
23. WHO. Haemoglobin concentration for the diagnosis anaemia and assessment of severity. Vitamin and Mineral Nutrition Information System. Geneva 2011.

24. Prutki M, Poljak-Blazi M, Jakopovic M, Tomas D, Stipancic I, Zarkovic N. Altered iron metabolism, transferrin receptor 1 and ferritin in patients with colon cancer. Cancer Lett. 2006;238:188-196.

25. Boutou AK, Pitsiou GG, Stanopoulos I, Kontakiotis T, Kyriazis G, Argyropoulou P. Levels of inflammatory mediators in chronic obstructive pulmonary disease patients with anemia of chronic disease: A case-control study. QJM. 2012;105:657-663.

26. Bray F, Ren JS, Masuyer E, Ferlay J. Global estimates of cancer prevalence for 27 sites in the adult population in 2008. Int J Cancer. 2013;132:1133-1145.

27. Oguz A, Colak D, Ersoy U, et al. The effect of haematological parameters on overall survival in advanced stage non-small cell lung cancer. Int J Hematol Oncol. 2014;24:82-88.

28. Macciò A, Madeddu C, Gramignano G, et al. The role of inflammation, iron, and nutritional status in cancer-related anemia: Results of a large, prospective, observational study. Haematologica. 2015;100:124-132.

29. Gioulbasanis I, Georgoulias P, Vlachostergios PJ, et al. Mini Nutritional Assessment (MNA) and biochemical markers of cachexia in metastatic lung cancer patients: Interrelations and associations with prognosis. Lung Cancer. 2011;74:516-520.

30. Alves de Rezende $\mathrm{CH}$, Marquez Cunha T, Alvarenga Junior V, PenhaSilva N. Dependence of Mini-Nutritional Assessment scores with age and some hematological variables in elderly institutionalized patients. Gerontol. 2005;51:316-321.

31. Guigoz Y. The Mini Nutritional Assessment (MNA ${ }^{\circ}$ ) review of the literature - What does it tell us? J Nutr Health Aging. 2006;10:466.

32. Ganz T. Macrophages and systemic iron homeostasis. J Innate Immun. 2012;4:446-453.

33. Roy CN. The anemia of inflammation and chronic disease. In: Anderson GJ, McLaren GD, eds. Iron Physiology and Pathophysiology in Humans. New York, NY: Humana Press; 2012:303-320.

34. Erslev AJ. Anemia of chronic disease. In: Beutler E, Lichtman MA Caller BS, Kipps TS, eds. Williams Hematology. $5^{\text {th }}$ ed. New York, NY: McGraw-Hill; 1995:518-524.

35. Akobeng AK. Understanding diagnostic test 1: Sensitivity, specificity and predictive values. Acta Paediatrica. 2006;96:338-341. 